\title{
JOVENS E VIOLÊNCIA: \\ UM ESTUDO SOBRE COMENTÁRIOS DE NOTÍCIAS NO FACEBOOK
}

\author{
YOUNGS AND VIOLENCE: \\ A STUDY ON FACEBOOK NEWS COMMENTS
}

\author{
Tânia Maria Rechia Schroeder ${ }^{1, *}$ \\ Claudia Barcelos de Moura Abreu²
}

\begin{abstract}
RESUMO: O presente ensaio apresenta reflexões sobre comentários de internautas a respeito de jovens e violência na cidade de Cascavel (PR). Os comentários foram extraídos no Facebook da Central Gazeta de Notícias (CGN), que disponibiliza os boletins de ocorrência da Polícia Militar. Trata-se de uma pesquisa etnográfica virtual, cuja estratégia metodológica está ancorada na sociologia do cotidiano de Maffesoli e nos fundamentos da violência antropológica de Girard. Constatou-se a presença de emoções compartilhadas que remontam a alguns arcaísmos, destacando-se o mecanismo do bode expiatório.
\end{abstract}

Palavras-chave: Jovens. Violência. Internet. Pós-modernidade.

\begin{abstract}
This essay presents reflections on comments of internauts about young people and their involvement in violence in the city of Cascavel, Paraná, Brazil. The comments were extracted from a Facebook page of CGN (Central News Gazette; in Portuguese, Central Gazeta de Notícias), which provides military police occurrence reports. It is a virtual ethnographic research, whose methodological strategy is anchored in Maffesoli's epistemological foundations of everyday life sociology, as well as in Girard's anthropological violence. It was observed in the comments the presence of shared emotions that go back to some archaisms, emphasizing the mechanism of the scapegoat.
\end{abstract}

Keywords: Young. Violence. Internet. Postmodernity.

\footnotetext{
1.Universidade Estadual do Oeste do Paraná - Programa de Pós-Graduação em Educação - Cascavel (PR), Brasil. 2.Universidade Federal de São Paulo - Programa de Pós-Graduação em Educação - São Paulo (SP), Brasil.

*Autora correspondente: tania.rechia@hotmail.com

Dossiê organizado por: Joyce Mary Adam e Débora Cristina Fonseca
} 


\section{Introdução}

Este ensaio apresenta reflexões sobre os comentários dos internautas na página de Facebook da CGN (Central Gazeta de Notícias) a respeito de jovens e seus envolvimentos com violência, segundo a perspectiva da razão sensível de Maffesoli (1998), a qual busca transcender as demarcações do racionalismo moderno, incorporando elementos advindos da emoção, das paixões, dos afetos e dos sentimentos, tão presentes nos elos societais pós-modernos.

Trata-se dos resultados de uma pesquisa que se iniciou no Brasil com o acompanhamento diário de notícias e dos seus respectivos comentários na página de Facebook da CGN durante um período de quatro meses, de dezembro de 2015 a abril de 2016.

A delimitação de idade para a coleta de dados seguiu a Lei Federal n. 12.852, sancionada em 5 de agosto de 2013, que, para fins de implementação de políticas públicas, considera jovens as pessoas na faixa etária entre 15 (quinze) e 29 (vinte e nove) anos. Considerando esse recorte etário, pesquisas como as do Núcleo de Estudos da Violência da Universidade de São Paulo (NEV/USP) têm evidenciado alta vulnerabilidade dos jovens residentes nos designados bairros problemáticos das capitais brasileiras, além de uma interiorização das violências, como pode ser evidenciado em Cascavel por meio dos dados estatísticos do Mapa da Violência de 2013, cujas taxas de homicídio de jovens do sexo masculino são as mais elevadas. Tal cenário reforça a relevância de estudos que articulem as juventudes e os contextos de violência.

Num segundo momento, os dados foram analisados teoricamente durante o período de agosto a dezembro de 2016, em estágio pós-doutoral realizado no Centre d'Etude sur l'Atual et le Quotidien (CEAQ), na Université Paris - Sorbonne/René Descartes, sob orientação de Michel Maffesoli, professor emérito e membro honorário do Instituto Universitário da França ad vitam, considerado um "pensador da contemporaneidade" ou da "pós-modernidade" (MAFFESOLI; FISCHER, 2016, p. 13). Segundo o autor, o tempo presente pode ser analisado a partir de uma razão que ele chama de "sensível" (MAFFESOLI, 1998), com vistas a examinar os fenômenos sociais de modo a encontrar a raiz da vida em conjunto a partir de sua própria lógica, não de pré-julgamentos. Em síntese, por meio de uma metodologia formista, o autor propõe descrever a vida tal como ela é em vez de prescrever como ela deveria ser.

Num terceiro momento, realizamos um aprofundamento sobre os valores da pós-modernidade na perspectiva de Michel Maffesoli, em estágio pós-doutoral realizado no Programa de Pós-Graduação em Educação (PPGE) da Universidade Federal de São Paulo (UNIFESP), durante o período de janeiro a dezembro de 2017, por meio do Programa Nacional de Pós-Doutorado (PNPD) da CAPES.

Os estudos foram realizados a partir da constatação de que estamos vivendo um momento de grandes metamorfoses e de que um novo ciclo está emergindo: o ciclo da pós-modernidade, que se caracteriza como a "[...] synergie de l'archaïque et du développement technologique" (MAFFESOLI, 2018, p. 135). É possível observar, na vida cotidiana, um retorno a valores arcaicos junto ao desenvolvimento tecnológico, valores esses mais perceptíveis nas novas gerações.

\section{Jovens e Violência no Facebook}

A CGN publica, em sua página de Facebook, os boletins de ocorrência da Polícia Militar. Possui, em média, doze milhões de visualizações ao mês e é uma das páginas mais populares da cidade 
de Cascavel (PR). Metodologicamente, a pesquisa amparou-se na perspectiva da fenomenologia formista (descrição, intuição, metáfora) de Maffesoli (1998) e nos princípios da etnografia (GEERTZ, 1989; HINE, 2004; 2015). ${ }^{1}$

Acompanhamos a página da CGN de maneira circunscrita e específica, observando perifericamente os comentários publicados diariamente relacionados às notícias sobre o envolvimento de jovens com a violência, tanto como protagonistas quanto como vítimas. Nesse exercício de pesquisa em ambiente virtual, a finalidade é observar o comportamento dos atores sociais e o modo como os comentários constituem uma comunidade afetiva, que envolve uma cultura fragmentada e emocional.

Ao prestar atenção a situações cotidianas consideradas banais, percebemos que muitos excessos advindos de paixões e emoções que fazem parte da vida social têm sido intensificados por meio da Internet, a qual, embora apresente um aspecto perverso de disseminação rápida de ideias preconceituosas e estigmatizantes, possui, também, um aspecto lúdico e irônico, que favorece a partilha de ideias e de sentimentos comuns. Os comentários dos internautas revelam os aspectos do bem e do mal constituintes da natureza humana. A Internet vem engendrando metamorfoses sociais de tal profundidade que, segundo Maffesoli, em diálogo com Fischer, precisamos encontrar novas formas de observação e palavras para descrever a mudança de paradigma que está em curso, a qual, por enquanto, os autores vêm denominando pós-modernidade:

On quitte la "Galaxie Gutenberg" pour um autre univers qui reste à évaluer et à apprécier. Comme tout changement de paradigme, la galaxie Internet (la cyberculture sous ses diverses modulations) représente une mutation fundamentale, c'est cela que, faute ou mieux, on peut nommer: postmodernité. (MAFFESOLI; FISCHER, 2016, p. 25)².

É possível observar, no cotidiano, que os elos sociais não se limitam aos aspectos contratuais, mas se fixam em identificações que estimulam uma estética comum, cujas vibrações emocionais se propagam numa rapidez assombrosa, graças à Internet. Por meio do Facebook, bem como de outros espaços virtuais, o que é privado se torna público e as diferentes tribos divulgam seus próprios saberes, interagindo com tribos antagônicas e/ou complementares.

La pensée commune, les idéologies «tribales » : forums de discussion, réseaux sociaux, sites communitaires, voilá autant d’aspects de la mutation en cours. Tout à coup, on voit bien que l'individu ne pense pas mais « qu'il est pensé », « on » le pense. Ce passage du « je » au «nous » est pour moi un changement fondamental dans notre societé (MAFFESOLI; FISCHER, 2016, p. 25) $)^{3}$.

Um dos valores pós-modernos destacados por Maffesoli é o tribalismo caracterizado pela ideia de compartilhamento (partager), o qual se diferencia do individualismo que marcou a economia moderna. Para o autor, as tribos e comunidades ressurgem nos compartilhamentos de casas, carros, escritórios etc. "Estar com" é marca fundamental de um societal participativo, colaborativo e mutualista, que se nutre de sonhos, fantasmas e fantasmagorias das múltiplas tribos que estruturam as sociedades pós-modernas, uma vez que o real está impregnado de irreal. Isso significa que os vínculos sociais abrangem certa dose do não racional possível de se perceber nas ritualizações esportivas, consumistas, musicais e, também, nas espontaneidades manifestas no cotidiano das redes sociais.

Como categoria de análise, a noção de tribo recebe críticas no Brasil, sobretudo aquelas articuladas ao debate em torno das "culturas juvenis". Magnani (2005) sustenta que existe um mal-entendido recorrente ao vincular-se o conceito de tribo urbana ao conceito clássico utilizado pela etnologia. Para tal autor, é mais interessante o termo "culturas juvenis", uma vez que permite um trânsito conceitual na direção dos atores, das identidades e das estratégias ${ }^{4}$. 
Em que pesem as críticas relacionadas à utilização de "tribos urbanas" como categoria de análise ou como metáfora, para nos referirmos aos internautas que se agrupam em torno de discussões na Internet, optamos teoricamente pelo uso dessa expressão, seguindo o mesmo raciocínio de Maffesoli (2000), o qual a utiliza como metáfora para se referir a agrupamentos sociais que partilham emoções. As manchetes da CGN, vinculadas aos boletins policiais a respeito de jovens e violência, por exemplo, estimulam a formação de agrupamentos com variadas nuances:

Batida deixa rapaz ferido/ Rapaz é atropelado pela namorada/ Adolescente é detido após danificar viatura/ Jovem se fere ao cair da escada/ Rapaz depõe e assume ter atirado/ Garota é apreendida após esfaquear o pai/ Em acidente, jovem de 20 anos fica ferida/ Menor é detido com maconha no calçadão/ Jovem é detido com maconha/ Jovem leva tiro de raspão na cabeça/ Rapaz é pego com revólver calibre 32/ Jovens tem celulares roubados em assalto/ Jovem é detido acusado do crime de furto/ Rapaz é pego dormindo em veículo furtado (notícias no Facebook da CGN, 2016).

Observamos que a incidência de notícias que envolviam jovens do gênero masculino era consideravelmente superior às que envolviam jovens do gênero feminino. No entanto, os comentários dos internautas em relação às notícias sobre jovens mulheres, além de aparecerem em maior volume, relacionavam-se à moral em relação a sexualidade e liberdade femininas. A notícia "Garota é apreendida após esfaquear o pai” suscitou opiniões que oscilavam entre julgar, condenar, absolver, ironizar etc.

As manchetes nas telas dos celulares ou dos computadores fomentam a formação de comunidades com diversas figuras, que aludem ao pai, à mãe, ao carrasco, ao juiz, ao apaziguador etc. São palavras e imagens que favorecem reconhecimento ou rejeição de determinados grupos, bem como um lugar de encontro e catarse de sentimentos comuns sobre os jovens. Para Maffesoli (2012, p. 91), “[...] o espaço cyber desempenha de novo o papel da praça pública, do café do comércio ou da ágora antiga: assim correm boatos, buzz, fofocas e outras novidades verdadeiras ou falsas".

- Fácil julgar! Só quem tem pai violento sabe o inferno que eh! - Lamentável o cara bebe tipo loco no bar, chega em casa virado no mais velho e ainda sai de vítima! - Por mais que o pai seja "bêbado" não justifica esfaqueá-lo, pow é pai cara! Daí o cara morre, e vai lá chora no velório de remorso. - Corresse dele, não tem pernas essa moça? Espera-se passa o efeito da bebida e resolvessem como gente. - Isso é um pecado, fuja peça ajuda, grite por socorro! Mais jamais em hipótese algum levante a mão contra seus pais. - Eu sei o que é ter pai violento, mais nem por isso matei pai ou mão essa menina é sangue ruim devia ser jugada na rua quando nasceu. - E o Espírito natalino hohoho. - Pobres filhos com pais alcoólatras. - Misericódia (comentários de internautas no Facebook da CGN, 2016).

Destacamos aqui as suposições dos internautas em relação aos motivos que impeliram a jovem a tal ação. As divergências de opinião geram desavenças entre os internautas, a tal ponto que, em alguns casos, a emoção partilhada importa mais que as notícias. Trata-se de emoções de tal ordem que os fatos desaparecem diante da rivalidade que surge entre os que comentam, como ocorreu com a notícia de uma jovem desaparecida de 17 anos e foi encontrada no dia seguinte. Os internautas se manifestam num movimento entre condenar, defender ou, ainda, imaginar o que ela teria estado a fazer nesse tempo.

Como que por contágio, o seu retorno, sã e salva, manifesta-se numa profusão de julgamentos, revoltas, gozações, rotulações, discriminações, sarcasmos, ironias e, também, defesa da jovem. Mesmo que 
acreditem que os jovens sejam um grave problema social a ser solucionado com o recrudescimento das leis, há aqueles que desestruturam a sisudez dos comentários com gracinhas e deboches:

- Se fosse minha filha levaria uns bons tapas pra tomar vergonha na cara. - Coloquem ela pra lavar louça e trabalhar muito. - Tem que ensinar esta cambada de jovens que a vida não e confundir Liberdade com Libertinagem. - Eu se fosse sua mãe já teria te deixado mais malhada que vaca leiteira. - Quanta novidade q ela apareceu, passem a mão na cabeça q de onde veio essa tem mais. - CGN está passando vergonha [...] já sabe que estas gurias saem pra ficar com esses mulekes calça caída e depois voltam pra casa como se nada tivesse acontecido e a CGN colaborando pra essa vergonha. - Fiquei sabendo por alguma pessoa que ela estava na casa de um rapaz e depois de 9 meses vc vê o resultado \#oremos. - Você tava com ela pra saber? Se tem provas você pode falar, caso contrário é difamação querido, e isso é crime previsto no Código Penal [...] Mais Deus nesse seu coração e vontade de cuidar da SUA vida! - Você é advogada da moça? - Pode até não ser advogada, mas está certa. Muito fácil julgar pra quem está de fora. - AINDA não sou, mas estudo pra isso. Porém, não é preciso ser advogado (a) pra conhecer os direitos fundamentais de uma pessoa e ter a noção do que pode e não pode. - De menor pode sumir, matar, roubar enfim tudo q está no código penal eles podem porém sem nenhuma punição então continuem passando a mão nas cabeças desses adolescentes q o futuro será tão bom quanto o presente q estamos vivendo. Glória a Deus sabe (comentários dos internautas no Facebook da CGN, 2016).

As conotações de que menores de idade podem sumir, matar e roubar sem nenhuma punição foram significativas nos comentários dos internautas. Foi frequente, inclusive, a afirmação de que a origem dos problemas escolares residia no fato de que "os jovens podem fazer tudo" e os "professores não podem fazer nada", além de ter sido citado que o aumento dos problemas com os jovens nas escolas e o aumento da criminalidade estariam relacionados à impunidade.

Tais afirmações denotam que o "fantasma totalitário" nos ronda e pode exercer seu poder nos momentos em que houver brechas nas instituições, entre elas as educacionais, que lhes fornecem as bases de sustentação sob a justificativa do cuidado e da segurança para todos (MAFFESOLI, 2001, p. 17).

Para Maffesoli, a violência totalitária se manifesta no confronto de valores, uma vez que refutar as diferenças não condiz com a realidade empírica, permeada por múltiplas concepções.

A adoção da Norma cria um centro (ou centros) e periferias. O louco, o anormal não está mais integrado numa organicidade social da qual ele é parte integrante; ele entra na grande categoria dos excluídos que não podem submeter-se à dominação absoluta da razão. Essa dominação é insidiosa, ela se ramifica no conjunto do corpo social e produz o reino da equivalência generalizada, o que significa que a determinação da normalidade não pode suportar a diferença (MAFFESOLI, 1987, p. 22).

$\mathrm{Na}$ esteira do pensamento maffesoliano, a diferença é a fonte da vida. Dito de outro modo, é a heterogeneidade que mantém a saúde social. Ao não suportarmos a diferença, exercemos a inquietante violência que tanto nos envolve cotidianamente. Os excluídos têm exercido um papel de "bode expiatório" nas histórias humanas.

Girard (1990, p. 25), em seus estudos sobre o processo civilizatório a partir das tragédias gregas e da psicanálise, afirma que a lista das vítimas sacrificáveis é bem diversificada: “[...] os prisioneiros de guerra, 
os escravos, as crianças e os adolescentes solteiros, os indivíduos defeituosos, ou ainda a escória da sociedade, como o pharmakós grego". Ao analisar as primeiras instituições sociais e culturais do Ocidente, o denominador comum que esse autor encontrou para a escolha das vítimas expiatórias foi uma ligação vulnerável ou nula com a sociedade.

Assim, a vítima é alguém à margem da sociedade, diferente, e que, por isso, atrai desconfiança: "Algumas vezes é o estatuto de estrangeiro ou de marginal, outras a idade ou a condição servil que impedem às futuras vítimas a plena integração na comunidade" (GIRARD, 1990, p. 25). Nessa lógica, a solução seria canalizar gradualmente os conflitos, ódios e ressentimentos sobre um único indivíduo: o "bode expiatório". É sobre ele que a comunidade deposita a responsabilidade da desordem e, uma vez expulso esse elemento, a paz e a ordem social voltariam a reinar, reforçando na comunidade a crença de que aquele indivíduo era o responsável pelos problemas coletivos.

Conforme assinala Maffesoli (1987; 2000; 2002) e Maffesoli e Fischer (2016), as ritualizações exteriorizam a violência e podem evitar que essa mesma energia, quando interiorizada, transforme-se em violência sanguinária e incontrolável. É possível observar que o ciberespaço possibilita catarses do aspecto obscuro da humanidade em doses homeopáticas ou paroxísticas, pois propicia a exteriorização das inconformidades que se manifestam sob a forma de infâmias protegidas pelo espaço virtual. Os comentários oscilam entre a severidade e a zombaria, como é possível observar na manchete "Menor atrapalha aula com moto barulhenta":

- Tem que pegar esse merda e colocar a orelha dele na ponta do escape e corta de giro só pra deixar ele meio surdo só pra ver como incomoda essa bosta barulhenta. - Tem gente que tem cabeça só pra separar as orelhas e criar piolho mesmo. - Meu sonho é dar um tiro de $12 \mathrm{em}$ uma moto dessas qdo passa. - Não pega nem gripe e fika querendo se aparece na frente da escola... otario mirim. - Só pra encher o saco... tem que ligar um trator e acelerar na orelha desses otários... molecada só pra incomodar. - Idiota kkkkkkkkkk burro a makonha tomo conta da mente desse loko. - Tomo grandão esse Imbecil/Se fudeu. É só vagabundo q faz isso (comentários dos internautas no Facebook da CGN, 2016).

A possibilidade de comentar as notícias no Facebook pode ser uma válvula de escape contra a angústia da existência, uma vez que é possível perceber que os internautas não buscam apenas notícias, mas também um lugar de encontro cotidiano para inteirar-se da crônica local e integrar-se na comunidade. Não queremos aqui enaltecer opiniões que prejudiquem a convivência social, pois a Internet cria espaços de discussão e de divulgação com variadas nuanças. O problema ocorre quando há uma predominância de expressões que fomentam a estigmatização social dos jovens, gerando, assim, nesse desequilíbrio de forças, imaginários sociais de jovens como uma ameaça social.

Os internautas comentam as notícias numa vibração que favorece a formação de tribos, que compartilham emoções e sentimentos advindos de seu imaginário a respeito dos jovens e seu envolvimento com violências. Isso, no entanto, não significa que as pessoas permaneçam numa mesma tribo. Elas circulam por diversas tribos, com suas diferentes máscaras, dependendo de seus desejos, o que configura o que já apontamos em trabalho de pesquisa anterior sobre o que Maffesoli compreende como tribalismo, nomadismo e hedonismo (SCHROEDER; ABREU, 2018).

Algumas notícias banais, como a do menor que atrapalhou a escola com moto barulhenta, provocam comentários que exprimem desejo de vingança, o que demonstra a utilidade da Internet para a exteriorização da violência. De acordo com Maffesoli, em debate com Fischer: 


\begin{abstract}
Nous avons oublié que notre espèce est animale: l'animal humain est, aussi, animal. Il faut donc savoir gérer cette énergie, ce dynamisme. Violence vient du mot « vis » qui signifie force en latin. Il faut donc apprendre à gérer cette " force » (violence) individualle et collective. Ainsi, il n’est pas « inutile » qu'il y ait tout et n’importe quoi sur l'Internet : «ça » purge. L'interdiction nest jamais judicieuse! C’est la vieille idée de la catharsis. C’est une sagesse populaire que la philosophie aristotélicienne reprend à son compte dans l'idée de purgation. Si on ne sait « purger » il y a explosion (MAFFESOLI; FISCHER, 2016, p. 97-98)5.
\end{abstract}

Ademais, a violência apresenta uma constância nas histórias humanas, envolvendo múltiplos valores e significados, que se relacionam com o tempo e o lugar em que acontece. Portanto, importa prestar atenção ao aspecto estrutural e antropológico da violência (MAFFESOLI, 1987; 2001).

Girard (1990), ao analisar as sociedades tribais baseadas no sacrifício, afirma que, nessas sociedades, um ato de violência gera necessariamente outro ato, que, por sua vez, gerará outro, numa escalada de vingança e de contágio de violência incomensurável.

Desse modo, o sacrifício seria uma medida para prevenir a violência entre os membros dessas sociedades. A vítima não necessariamente é culpada de algo, mas é sacrificada a um deus em nome de toda a comunidade, como tributo pago a fim de prevenir a violência intestina. Então, a vítima seria o bode expiatório do "crime" de todos. Mesmo assim, no entanto, para que o sacrifício conquiste a restauração da paz, a comunidade tem que estar convencida de que a vítima é culpada.

Girard (1990, p. 32) se refere ao sacrifício da vítima expiatória como ritual típico das sociedades primitivas, realizado para conter o círculo vicioso da vingança e aquietar os impulsos violentos. Na atualidade, esse círculo não existe, uma vez que o sistema judiciário detém a última palavra. Muito embora o sistema judiciário não elimine a vingança, ele a limita a uma única revanche, racionalizando a violência. Contudo, “[...] é incorreto afirmar que o sacrifício ‘substitui’ o sistema judiciário".

Concordamos com Girard (1990) ao assinalar que não podemos julgar as sociedades primitivas como inferiores a nós por não possuírem um sistema judiciário. Tampouco podemos avaliá-las como superiores, dado que é inviável mensurar a intensidade da violência dos indivíduos e das sociedades. Numa sociedade que não dispõe de sistema judiciário, a violência não aparece sob as mesmas formas nem nos mesmos lugares. Contudo, o princípio é o mesmo: a reciprocidade violenta.

Nas sociedades primitivas, derramava-se sangue com a consciência tranquila, destruindo o que fosse necessário. Hoje - "civilizados" -, o derramamento de sangue para sacrifício, seja de seres humanos ou de animais, é inaceitável. No entanto, da barbárie artesanal de séculos anteriores, passamos para a sofisticação dos meios propiciados pelo avanço tecnológico e pelo desenvolvimento científico para a realização de guerras, carnificinas, genocídios, racismos e os diversos processos de exclusão que caracterizam a vida cotidiana.

Não é mais aceitável o derramamento de sangue nos templos e nos altares, mas não há como negar, na esteira de Girard, que as vítimas de hoje têm semelhanças com as vítimas dos sacrifícios realizados nas sociedades primitivas. Para Girard (1990), muitas discriminações que ferem o ser humano são legitimadas pelo mecanismo do bode expiatório. Jovens, estrangeiros, imigrantes, minorias, entre outros, são considerados culpados pelas crescentes crises de determinados países e apontados como a origem de diversos problemas sociais, econômicos e políticos.

Ao tomarmos partido pela segregação de grupos, de bairros, de locais e/ou de pessoas, agimos com discriminação, o que pode gerar outras violências. Considerando que a violência apresenta uma constância na história, sob diversas formas, Maffesoli e Fischer (2016) propõem compreendê-la como um eterno confronto presente nas sociedades. Os autores afirmam ser preciso saber ritualizá-la. 
Concernant la violence, mon hypothèse a toujours été de considérer qu'il n’y a pas assez de violence dans nos societés. Et qu'en évacuant les formes ritualisées de violence on favorise le développement d'un ennui mortifère. En effet, c'est quand on ne sait pas ritualiser la violence que celle-ci devient perverse, «per via ». Elle devient sanguinaire et immaîtrisable (MAFFESOLI; FISCHER, 2016, p. 97)

Embora a Rede Mundial de Computadores e as mídias televisiva, escrita e falada divulguem, em tempo real, todo tipo de violências que ocorrem cotidianamente, estimulando o crescimento do medo generalizado, observamos, também, que a Internet possibilita encontros e trocas catárticas, uma vez que o fervor para a destruição está nas tramas de toda a estruturação social.

Inspirando-nos em Maffesoli (2018; 2012; 2000) e Maffesoli e Fischer (2016), cabe afirmar que a sociedade pós-moderna se caracteriza pela sinergia entre o arcaico e o desenvolvimento tecnológico. As tribos pós-modernas se formam e se desfazem rapidamente graças à Internet. Eis aí um aspecto interessante e paradoxal, pois, se do século XIX até meados do século XX, a tecnologia era utilizada para a racionalização da vida em sociedade, numa tentativa de excluir questões que viessem da ordem do emocional, atualmente constatamos justamente o contrário, uma vez que a mesma tecnologia vem promovendo o retorno de aspectos arcaicos relacionados a tribalismo, nomadismo e hedonismo.

\section{Considerações Finais}

Neste ensaio, apresentamos parte de uma pesquisa etnográfica virtual, na qual acompanhamos notícias e os respectivos comentários sobre os jovens e seu envolvimento com a violência na cidade de Cascavel (PR).

O ponto de partida de nossas análises foi de que vivemos numa época compreendida como pós-moderna e que se caracteriza como um tempo de emergência de valores arcaicos com o desenvolvimento tecnológico. Podemos afirmar que o desenvolvimento tecnológico, neste caso, representado pela Internet e por suas ferramentas, tem facilitado a disseminação de arcaísmos via Facebook, WhatsApp, Twitter, YouTube, entre outras redes sociais, pelas quais é possível perceber, além de comentários sobre publicações de notícias, a vertiginosa circulação de valores pós-modernos, perceptíveis em correntes de oração, simpatias, promessas a santos, meditações, comercialização de produtos orgânicos locais, medicamentos naturais, erotismos, violências etc.

As comunidades virtuais se agrupam por identificações advindas de variados interesses, como o cotidiano, a religião, a política, as viagens, a música, a culinária, a saúde, o esoterismo, o amor, entre outros. É nesses espaços que as pessoas trocam experiências, discutem e participam de variados temas sem necessariamente ser especialistas no assunto. É também neles que conseguimos perceber o que Maffesoli (2001) chama de "atmosfera mental", um "estado de espírito" de um tempo e de um lugar que, para ele, seriam o imaginário social.

As crônicas locais típicas das sociedades pré-modernas ganham força com a Internet. $\mathrm{O}$ Facebook e demais redes sociais restabelecem o que Maffesoli denomina ideal comunitário, seja para o bem ou para o mal. Desse modo, é possível observar o retorno das histórias locais que reforçam as relações com os outros.

A severidade de punições sugeridas por alguns internautas nos levou aos estudos de Girard (1990), o qual nos auxiliou na compreensão de que a prática arcaica do mecanismo do "bode expiatório" persiste em nossos dias e tem ganhado força com as redes sociais. Embora não seja nossa intenção 
considerar, de maneira ingênua e dualista, que existe, de um lado, o bom jovem e, de outro, o adulto mau, tampouco o jovem mau diante do indefeso adulto, é importante atentar para a construção de um imaginário social a respeito de jovens, imaginário esse que se expressa por meio de um sentimento de insegurança, como se os jovens representassem ameaça maior do que aquela que os dados estatísticos demonstram (haja vista os dados de mortalidade de jovens, com destaque para os jovens homens negros moradores das periferias).

Cabe destacar que, embora os jovens não sejam os únicos a praticar crimes, vêm sendo focalizados de maneira contundente nas representações sociais do desvio, tendo como suporte a imprensa. As experiências de ser jovem são variadas e dependem dos ambientes e contextos de sociabilidade em que se inserem. Os problemas com os quais os jovens se envolvem ganham outros sentidos quando se trata de jovens pobres da periferia. Para constatar isso, basta ver a conotação de perigo e ameaça à sociedade presente nos debates públicos e nas ações políticas que clamam por mais repressão.

Parece-nos, assim, que vivemos um tempo difícil para as novas gerações, em especial as que se encontram em situação de vulnerabilidade social. Afinal, como construir projetos de vida e ter perspectivas de futuro diante dos altos índices de violência? Como projetar o futuro numa sociedade que se transforma numa rapidez vertiginosa? Como planejar uma vida profissional em um contexto de mudança no mundo do trabalho cujas profissões que eram estáveis vêm se transformando continuamente e o emprego se tornou uma miragem?

Refletir sobre a relação entre jovens e violência, visto que os dados sobre homicídio nessa faixa etária são escandalosos, implica proposições de políticas públicas para a juventude que enfrentem a carência de oportunidades de trabalho, as exíguas possibilidades de lazer e os problemas de escolas com altos índices de evasão escolar. Embora as carências materiais e simbólicas estejam relacionadas aos atos de violência envolvendo os jovens, não devemos associar de maneira linear a violência urbana e a pobreza (GADEA, 2014), uma vez que há uma complexa combinação de variáveis relacionadas às primeiras experiências de socialização na família e à socialização secundária, comprometidas por carências materiais, educacionais, de inserção no mundo do trabalho e de alternativas de lazer.

Maffesoli, em suas argumentações, sem se situar como otimista ou pessimista, mas se contentando em descrever o que observa no cotidiano das cidades, afirma que os valores pósmodernos - dos quais ele destaca o tribalismo, o nomadismo e o hedonismo - são mais visíveis nas novas gerações. A valorização do presente, do aqui e do agora, relaciona-se a uma maneira de viver que não se angustia com o futuro. São as novas gerações que, também, possuem maior capacidade de adaptar-se às constantes mudanças sociais relacionadas às novas formas de aprender, habitar, comer, namorar, locomover-se, entre outras. Suas verdades são provisórias e múltiplas são as suas identificações (tribos), colocando em xeque o sujeito fechado em uma identidade fixa - seja ela sexual, ideológica ou profissional - típica da modernidade.

No prefácio da terceira edição de sua obra Le temps des tribos: Le déclin de l'individualisme dans les societés postmodernes, cujo título dado por Maffesoli (2000) é “Trouver les mots”, o autor argumenta que precisamos encontrar as palavras para descrever as grandes mutações sociais que estão em curso, e propõe a metáfora "tribo" para descrever o tribalismo pós-moderno visível na emergência de outras formas de "estar junto". Em sua mais recente obra, Etre Postmoderne, Maffesoli (2018) retoma essas questões e as atualiza, insistindo que tais transformações se relacionam, essencialmente, com vivências pautadas em valores pós-modernos. Suas análises sobre "tribos urbanas" contribuem significativamente para a reflexão do tema da juventude e seus projetos de vida, uma vez que nos fornecem chaves para a compreensão das dinâmicas de sociabilidade da juventude. 


\section{Contribución de las Autoras}

Problematização e Conceituação, Schroeder TMR, Abreu CBM; Metodologia, Schroeder TMR, Abreu CBM; Análise, Schroeder TMR, Abreu CBM; Redação, Schroeder TMR, Abreu CBM.

\section{REFERÊNCIAS}

BRASIL. Decreto-lei no 12.852, de 5 de agosto de 2013. Estatuto da Juventude. Congresso Nacional, Brasília, DF, 2013.

BRASIL. Censos Demográficos 2010. In: Instituto Brasileiro de Geografia e Estatística (IBGE), 2010. Disponível em: <http://www.ibge.gov.br/home> Acesso em: 18 out. 2017.

BRASIL. Homicídios e Juventude no Brasil. In: Mapa da Violência. Brasília, DF, 2013. Disponível em: <http://www.mapadaviolencia.org.br> Acesso em: 18 mar. 2017.

BOID, D. A Response to Christine Hine. 2008. http://doi.org/10.4135/9781483329086.n3

CGN. Central Gazeta de Notícias. Página do Facebook. Disponível em: <https://www. facebook.com>. Acesso em: 04 mar. 2015.

GADEA, C. A. Jovens, violência e contemporaneidade: Interpretações e desafios da escola. In: MALACARNE, V. et al. Violência e educação: Em busca de novos olhares. Curitiba: Editora CRV, 2014, p. 11-22.

GEERTZ, C. A interpretação das culturas. Rio de Janeiro: LTC, 1989.

GIRARD, R. A violência e o sagrado. São Paulo: Paz e Terra/Unesp, 1990.

GIUMBELLI, E. Para além do "trabalho de campo": Reflexões supostamente malinowskianas. Revista Brasileira de Ciências Sociais, São Paulo, v. 17, n. 48, p. 91-107, fev. 2002. https://doi.org/10.1590/ S0102-69092002000100007

HINE, C. Etnografía Virtual. Collección Nuevas Tecnologías y Sociedad, Barcelona: Editorial UOC, 2004

HINE, C.Por uma etnografia para a Internet: transformações e novos desafios. Entrevista concedida a Bruno Campanella. MATRIZes, v. 9, n. 2, p. 167-173, jul./dez., 2015. https://doi.org/10.11606/ issn.1982-8160.v9i2p167-173

MAFFESOLI, M. Être Postmoderne. Paris: Les Éditions du Cerf, 2018.

MAFFESOLI, M. O tempo retorna: Formas elementares da pós-modernidade. Trad. Teresa Dias Carneiro. Rio de Janeiro: Forense Universitária, 2012. 
MAFFESOLI, M. Entre o bem e o mal: Compêndio de subversão pós-moderna. Lisboa: Instituto Piaget, 2002.

MAFFESOLI, M.A violência totalitária. Porto Alegre: Sulina, 2001.

MAFFESOLI, M. Le temps des tribus: Le déclin de l'individualisme dans les sociétés postmodernes. Paris: La Table Ronde, 2000.

MAFFESOLI, M.Elogio da razão sensível. Petrópolis: Vozes, 1998.

MAFFESOLI, M. Dinâmica da violência. São Paulo: Editora Revista dos Tribunais/Edições Vértice, 1987.

MAFFESOLI, M; FISCHER, H. La postmodernité à l'heure du numérique: Regards croisés sur notre époque. Paris: Éditions François Bourin, 2016.

MAGNANI, J. G. C. Os circuitos dos jovens urbanos. Tempo social, São Paulo, v. 17, n. 2, p. 173-205, nov. 2005. https://doi.org/10.1590/S0103-20702005000200008

SCHROEDER, T. M. R.; ABREU, C. B. M. Pós-modernidade: Perspectivas de Jean-François Lyotard e Michel Maffesoli. Revista Educere et Educare, v. 13, n. 28, mai.-ago., 2018. http://dx.doi.org/10.17648/ educare.v13i28.20487

\section{Notas}

1. O método etnográfico e suas implicações no debate sobre a definição da antropologia como ciência são extremamente relevantes (ver GIUMBELLI, 2002), mas extrapolam os limites do presente ensaio. Importa destacar o movimento nas pesquisas que se alimentam dessa perspectiva metodológica a partir da popularização da Internet e do estabelecimento do campo virtual (ou cyber) como espaço legítimo de pesquisas sobre cultura. Nesse sentido os trabalhos de Christine Hine são fundamentais, pois destacam o potencial de interação e conexão que os grupos sociais exercem na Internet. Nos estudos da autora, fica claro o alto grau de flexibilidade interpretativa presente nas interações grupais no espaço on-line. Evidentemente, existe uma tensão na relação on-line vs. off-line, pela qual Hine recebe críticas. Para um aprofundamento, consultar Boyd (2008).

2. Deixamos a "Galáxia Gutenberg” para um outro universo que falta avaliar e apreciar. Como qualquer mudança de paradigma, a galáxia Internet (a cibercultura sob as suas diversas modulações) representa uma profunda mudança que, na falta de um nome melhor, chamamos pós-modernidade (tradução livre).

3. O pensamento comum, as ideologias "tribais": fóruns de discussão, redes sociais, sites comunitários, eis vários aspectos das transformações em curso. De repente, vê-se claramente que o indivíduo não pensa, mas é pensado. Essa passagem do "eu" para o "nós" é, para mim, uma mudança fundamental na nossa sociedade (MAFFESOLI, 2016, p. 25) (tradução livre).

4. É importante pontuar que a perspectiva teórico-metodológica adotada por Maffesolli, ao desenvolver a metáfora da tribo pós-moderna, não se baseia na etnologia clássica que propunha um olhar desde o centro dos grupos sociais, bemdefinidos e delimitados, estruturados em regras e costumes específicos. Mas, em sentido oposto, reforça o trânsito, 
o efêmero, o estético, o "viver com os outros". Nesse sentido, a crítica formulada por Magnani (2005) às tribos é importante, na medida em que suscita alguma limitação em termos definitivos, mas não diminui sua potência de analise em cenários nos quais o mais relevante é a fluidez.

5. Temos esquecido que nossa espécie é animal. O animal humano é, também, animal. É preciso saber lidar com essa energia, esse dinamismo. Violência origina-se da palavra “vis", que significa “força”, em latim. É preciso, então, aprender a lidar com essa "força" (violência) individual e coletiva. Assim, não é "inútil” a existência - de não importa o quê - na Internet: “isso” purga. A interdição não é judiciosa! É a velha ideia de catarse. É uma sabedoria popular que a filosofia aristotélica retomou ao seu modo - a ideia de purgação. Se a gente não sabe "purgar", há explosão (tradução livre).

6. No que concerne à violência, minha hipótese tem sido considerar que sempre haverá violência em nossas sociedades. E se evacuarmos as formas ritualísticas de violência podemos favorecer o desenvolvimento de um tédio mortífero. Com efeito, quando não sabemos ritualizar essa mesma violência torna-se perversa, "per via”. Ela se torna sanguinária e incontrolável (tradução livre).

Recebido: 01 Mar 2019

Aceito: 17 Set 2019

Comitê Editorial do Cedes/Coordenação deste número:

Izabel Galvão e Maria Rosa Camargo 